\title{
Requisitos de projeto para o desenvolvimento de embalagens com ênfase no consumidor
}

\author{
Lucas José Garcia \\ Universidade Federal de Santa Catarina \\ lucasjose@gmail.com \\ Daniel Theiss Ristow \\ Universidade Federal de Santa Catarina \\ ristowdaniel@gmail.com \\ Giselle Schmidt Alves Díaz Merino \\ Universidade Federal de Santa Catarina \\ gisellemerino@gmail.com \\ Leila Amaral Gontijo \\ Universidade Federal de Santa Catarina \\ leila.gontijo@ufsc.br \\ Eugenio Andres Díaz Merino \\ Universidade Federal de Santa Catarina \\ eugenio.merino@ufsc.br
}

Resumo: Aspectos relacionados a embalagem e marca podem ser considerados fragilidades do setor da maricultura no estado de Santa Catarina. Cada vez mais os consumidores exigem produtos que atendam suas demandas de praticidade e satisfação. Esta pesquisa tem como objetivo definir requisitos para o desenvolvimento de uma embalagem a partir de uma pesquisa realizada com consumidores em supermercados. A pesquisa foi realizada em duas etapas, a primeira, de cunho teórico, com levantamento bibliográfico, sendo a segunda de caráter prático, que consistiu no desenvolvimento de uma embalagem. Como resultados são apresentados os requisitos aplicados na embalagem, com por exemplo facilidade de leitura das informações, destaque para o prazo de validade e facilidade de abertura e fechamento, contribuindo para a promoção da satisfação dos consumidores/usuários na interação com o produto.

Palavras-chave: Design, Embalagem, Requisitos, Consumidor, Maricultura.

Abstract: Aspects related to packaging and brand may be considered weaknesses of the mariculture industry in the state of Santa Catarina. Increasingly, consumers want products that meet their demands for 
convenience and satisfaction. This research aims to define requirements for the development of a package from a survey with consumers in supermarkets. The survey was conducted in two stages. The first, a theoretical nature, with bibliographical survey; the second, with a practical character, which was the development of a packaging. As result are presented the requirements applied in packaging with eg readability of the information, highlighting the validity and ease of opening and closing, contributing to the promotion of consumer satisfaction in the interaction with the product.

Keywords: Design, Packaging, Requirements, Consumer, Mariculture.

\section{INTRODUÇÃO}

A aquisição de alimentos compreende questões como sustentabilidade, bem-estar, saúde e boa forma. Em relação aos produtos da maricultura (ostras e mexilhões) notase como principal dificuldade a comercialização, relacionada diretamente à falta de hábitos de consumo e dúvidas sobre à segurança alimentar (ALTMANN; MIOR; ZOLDAN, 2008). Os consumidores tornaram-se mais exigentes, demandando produtos que cumpram suas necessidades com uma percepção de qualidade excepcional, assim, marca e embalagem devem ser desenvolvidas com o consumidor em mente (HURLEY et al, 2013).

No passado, a embalagem continha a função principal de proteger e preservar seu conteúdo. Com o passar dos anos a embalagem passou a atender as exigências dos consumidores. Porém, os principais fatores de design considerados foram a redução de custos para os fabricantes e o potencial impacto sobre os consumidores. Atualmente, os principais fatores relacionados às embalagens dizem respeito à praticidade e à facilidade de uso (YOXALL et al, 2006). Embora os produtos sejam desenvolvidos para os consumidores, atendem-se inicialmente às especificações dos fabricantes. 0 desenvolvimento de produtos a partir das demandas de consumo pode ser realizado a partir da obtenção de requisitos dos consumidores (ROZENFELD, 2006).

O design pode contribuir ao colocar o ser humano como foco do projeto, orientando seus esforços no intuito de maximizar a experiência dos consumidores com o produto, por meio de embalagens mais fáceis de usar, abrir e higienizar, e rótulos fáceis de interagir, ler e com melhor acesso às informações (GARCIA, 2013).

Dentro deste contexto, esta pesquisa teve como objetivo definir os requisitos para o desenvolvimento de embalagens para um produto da maricultura, a partir dos resultados de uma pesquisa realizada com consumidores em supermercados de Florianópolis, onde estes foram abordados sobre hábitos de consumo de alimentos, sobre a percepção em relação a frutos do mar e a experiência no preparo e consumo de alimentos.

Apesar potencial produtivo do setor, os brasileiros não possuem hábito de consumo desses produtos. Os projetos relacionados à maricultura, em um grande número de casos, voltam suas ações principalmente para o aumento da oferta de produto, e não ao atendimento das demandas de consumo (OSTRENSKY; BORGHETTI; SOTO, 2008). Desta forma, embora o setor tenha crescido de forma rápida em Santa 
Catarina, supõem-se que não houve um planejamento eficiente em relação às questões relacionadas ao design, como identificação e apresentação dos produtos.

\section{METODOLOGIA}

A pesquisa foi realizada em duas etapas, a primeira descritiva e exploratória de cunho teórico, sendo a segunda etapa de caráter prático. Os procedimentos metodológicos adotados nesta pesquisa são apresentados a seguir.

Classificação da pesquisa: quanto ao seu objetivo, esta pesquisa pode ser classificada como descritiva e exploratória, pois esclarece conceitos e ideias para estudos posteriores e objetiva levantar opiniões, crenças e atitudes de uma população (GIL, 2008; GIL, 2010). Os dados são apresentados segundo a estatística descritiva, a partir da análise qualitativa e quantitativa, pois buscou-se investigar crenças, valores e atitudes de uma população, ao mesmo tempo que se utilizou de técnicas estatísticas por meio do uso de média, percentual e correlações (LAKATOS; MARCONI, 2009).

Procedimentos técnicos: para a realização da pesquisa utilizou-se de levantamento bibliográfico e formulário (Figura 1). A pesquisa bibliográfica caracterizase pela utilização de material já publicado (livros, periódicos, teses etc). Os formulários foram utilizados para coleta de dados primários e por oferecem subsídios para auxiliar no encaminhamento da pesquisa (GIL, 2010; RUTTER; ABREU, 1994).

Amostra: o universo da pesquisa abrangeu os indivíduos que realizam compras de alimentos em supermercados de Florianópolis, capital do estado de Santa Catarina. A amostra compreendeu 359 consumidores, que participaram de forma voluntária, selecionados segundo o critério de intencionalidade (GIL, 2010).

Coleta de dados ${ }^{1}$ : ocorreu em 7 estabelecimentos de Florianópolis, entre os dias 6 e 13 de novembro.
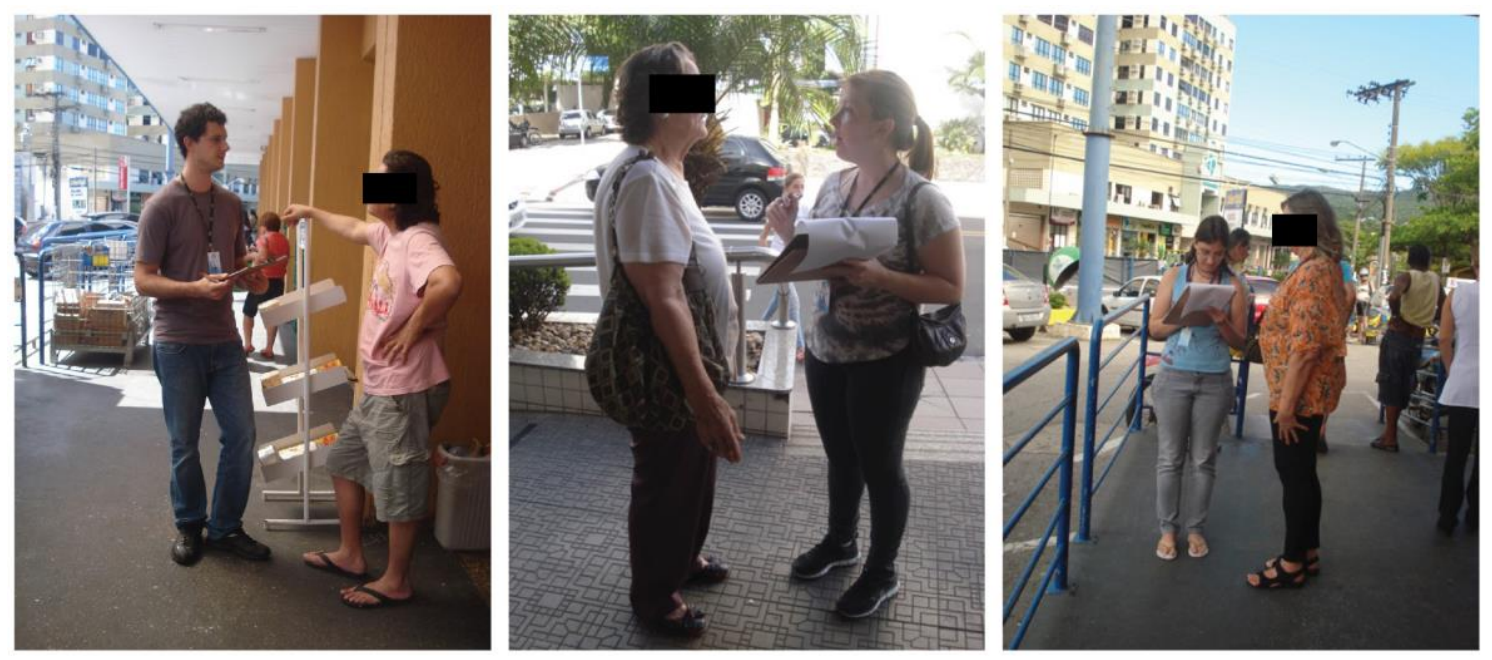

Figura 1 - Aplicação de formulários em estabelecimentos de Florianópolis. Elaborado pelos autores.

Formulário: foram utilizados formulários previamente estruturados, aplicados com pranchetas e canetas para o registro das informações. O formulário foi dividido em cinco partes, são elas: (i) aspectos relacionados à compra de alimentos com ênfase na embalagem e na rotulagem; (ii) aspectos relacionados ao uso da embalagem e

\footnotetext{
${ }^{1}$ Esta coleta de dados contou com a participação de discentes, a nível de graduação e pós-graduação, de Design e Engenharia de Produção da Universidade Federal de Santa Catarina.
} 
preparo de alimentos; (iii) consumo de frutos do mar; (iv) questões relacionadas à experiência do usuário na interação com embalagens e no preparo e consumo de alimentos; e (v) dados sócio demográficos.

Análise dos dados: a análise dos dados considerou: tabulação, ou transcrição no caso de questões abertas; discussão e análise estatística; e generalizações, para o caso específico. Foi utilizado o programa SPSS Statistics 17.0 para visualização dos dados e relacionamento entre variáveis.

Pesquisa aplicada: a pesquisa aplicada consistiu no desenvolvimento de uma embalagem a partir dos requisitos gerados com base nas informações coletadas dos consumidores. Para tanto foi utilizado o Guia de Orientação para o Desenvolvimento de Projetos (GODP).

O GODP apresenta um percurso configurado por oito etapas divididas em três momentos: inspiração (etapas -1, 0, 1), ideação (etapas 2, 3) e implementação (etapas $4,5,6)$, e propõem a consideração do consumidor/usuário como fator essencial para um projeto de design. Conforme definido por Merino (2013):

- Etapa -1 (Oportunidades) consiste no levantamento de oportunidades de mercado, onde são identificadas possíveis demandas para produtos ou serviços;

- Etapa 0 (Prospecção), é definida a demanda ou problemática central que norteará o projeto;

- Etapa 1 (Levantamento de dados) é realizado o levantamento de dados em diferentes fontes;

- Etapa 2 (Análise de dados) considera a organização e análise dos dados levantados anteriormente, para definição das estratégias de projeto;

- Etapa 3 (Criação) são gerados os conceitos e alternativas de projeto a fim de escolher o que melhor responda às especificações e objetivos;

- Etapa 4 (Execução) considera-se o ciclo de vida do produto em relação às propostas, ocorrem ajustes e organização da produção;

- Etapa 5 (Viabilização) ocorrem verificações e viabilizações da produção, testando o produto/serviço em situações reais, junto a usuários;

- Etapa 6 (Verificação), consiste em acompanhar e realizar verificações posteriores a produção, coletando e avaliando impactos. Esta etapa poderá gerar novas oportunidades, realimentando o ciclo.

Cabe ressaltar que os procedimentos adotados nesta pesquisa buscaram diagnosticar problemas com a finalidade de alcançar resultados práticos, em uma situação específica.

\section{MARICULTURA E DESIGN}

Embora a pesca tenha sido uma importante fonte de alimentos desde tempos remotos, atualmente a demanda por produtos oriundos desta atividade vem esgotando os recursos do planeta. Conforme exposto por Silveira e Silva (2011), na pesca o produto é extraído (retirado ou capturado) do ambiente, e em seguida encaminhado para venda, caracterizando a atividade como extrativista. Para Zhou, Ding e Wang (2012), a demanda por proteína animal para o consumo humano está em crescimento, e a aquicultura está a tornar-se uma fonte cada vez mais importante de peixes e mariscos para consumo humano. 
A aquicultura consiste num método no qual o produto é plantado, e após atingir tamanho adequado é colhido e encaminhado para venda, esse processo recebe o nome de cultivo e apresenta uma característica menos prejudicial ao meio ambiente. Esta atividade pode ser dividida entre o cultivo em águas doces e em águas salgadas, sendo a maricultura o termo que denomina o cultivo de organismos aquáticos em água salgada e abrange o cultivo de peixes, ostras, mexilhões, camarões, lagostas e algas, conforme apresentado na Figura 2 (SILVEIRA; SILVA, 2011).

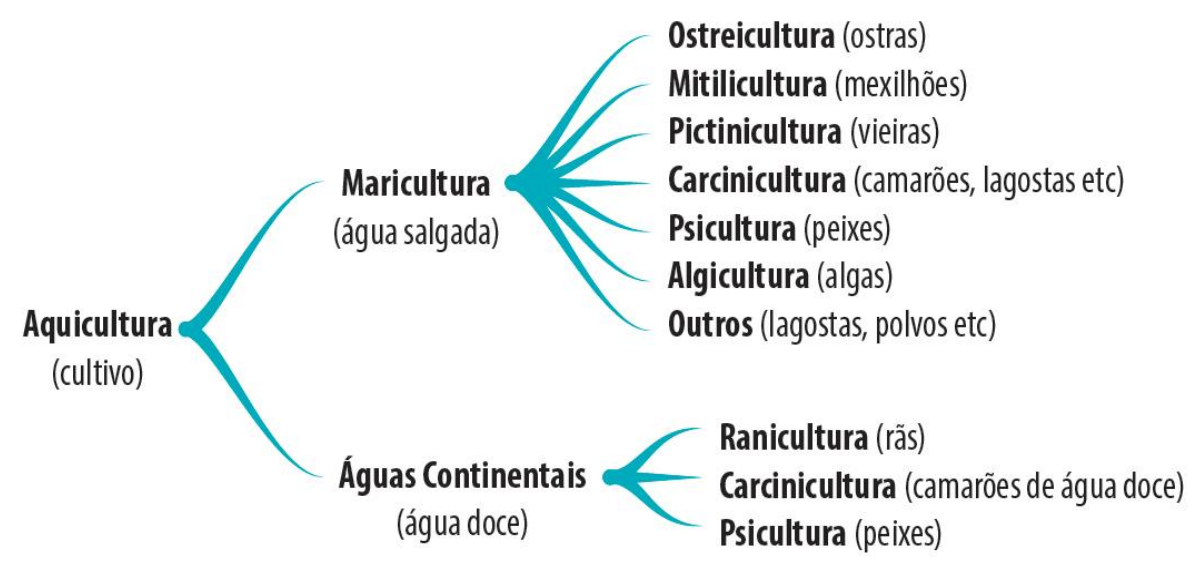

Figura 2 - Subdivisões da aquicultura. Adaptado de Silveira e Silva (2011, p. 125).

Segundo a FAO (Food and Agriculture Organization of the United Nations), o setor apresenta crescimento anual de 8,3\% (FAO, 2010) e, de acordo com a EPAGRI (Empresa de Pesquisa Agropecuária e Extensão Rural de Santa Catarina), cresce aproximadamente $6,5 \%$ ao ano, configurando-se como o setor de produção de alimentos de origem animal que mais cresce no mundo (SILVEIRA; SILVA, 2011).

No Brasil, a maricultura é de grande importância econômica. De toda a produção brasileira de moluscos, o estado de Santa Catarina é responsável por 95\% (PMF, 2013), destacando-se pela produção de moluscos como mexilhões e ostras (SILVEIRA; SILVA, 2011).

Aspectos relativos a embalagem, rótulos e marcas vem prejudicando a competitividade do setor, justificando assim a importância de desenvolver estudos e projetos na área que promovam o fomento entre estratégias de design e estratégias do produto (GARCIA; MERINO, 2008).

Dentre as contribuições oriundas do design, cabe citar a obtenção de novos consumidores para os produtos da maricultura por meio de ações de apresentação e comercialização dos produtos, como por exemplo marcas, embalagens e materiais de divulgação (GARCIA; MERINO, 2009) e a melhoria da qualidade de vida dos produtores e das comunidades onde vivem, influenciando na fixação dos trabalhadores em seus locais de origem pela definição de estratégias através da gestão de design (DICKIE, 2010). O design pode contribuir também para a valorização de produtos ao participar de forma ativa na melhoria da qualidade aparente dos produtos (MERINO; MERINO; FIGUEIREDO, 2007), e as embalagens, além de essenciais à conservação e transporte de produtos, podem funcionar como um atrativo ao consumidor (SILVA; PASCHOARELLI; SILVA, 2012).

A consideração das demandas dos consumidores para o desenvolvimento de projetos de embalagens, neste setor, pode auxiliar a minimizar as fragilidades que impedem um avanço significativo na comercialização dos moluscos em Santa Catarina. 


\section{RESULTADOS}

A pesquisa com consumidores foi realizada entre os dias 6 e 13 de novembro de 2012. Conforme citado anteriormente, foi utilizado um formulário, aplicado e preenchido por pesquisadores. Dentre os 359 formulários obtidos, 339 foram considerados válidos por estarem plenamente preenchidos. O perfil dos participantes da pesquisa é apresentado na Figura 3.

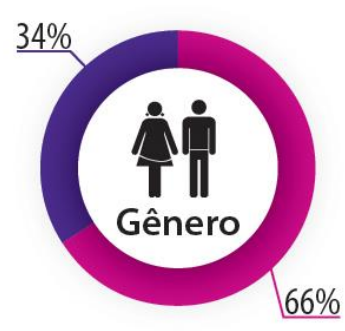

Masculino Feminino

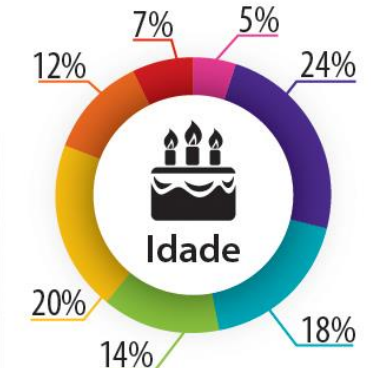

$14 \%$

Até 19 anos

De 20 a 29 anos

De 30 a 39 anos

De 40 a 49 anos

De 50 a 59 anos

De 60 a 69 anos

Mais de 70 anos

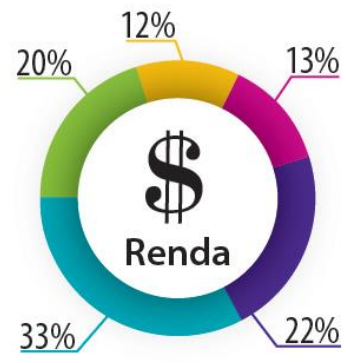

Até2 S.M.

De 2 a 4 S.M.

De 4 a 10 S.M.

De 10 a 20 S.M.

Mais de 20 S.M.

S.M.: Salários Mínimos, equivalente a $\mathrm{R} \$ 622,00$, durante a coleta de dados

Figura 3 - Dados dos participantes da pesquisa. Elaborado pelos autores.

Quando questionados sobre o que consideram importante em uma embalagem de produto de origem animal, 65\% dos consumidores (205 indivíduos) responderam a transparência da embalagem, 60\% (189 indivíduos) a validade, 51\% (161) a data de empacotamento e 47\% (148 indivíduos) a proteção. O material da embalagem, o tamanho, a cor, o desenho e a praticidade também foram citados, porém em menor escala.

Quando abordados sobre as informações que procuram na embalagem na hora da compra, $88 \%$ dos consumidores (293 indivíduos) citaram o prazo de validade, $43 \%$ (143 indivíduos) a tabela nutricional e 38\% (127 indivíduos) o preço. Dentre os pesquisados, 35\% (116 indivíduos) citaram procurar outras informações, dentre estas, obteve maior destaque o sódio. Cabe destacar que 71\% (164 indivíduos), relataram já ter apresentado dificuldade para encontrar o prazo de validade, enquanto $21 \%$ (49 indivíduos) tiveram dificuldade para encontrar a tabela nutricional.

$\mathrm{Na}$ hora de preparar o alimento, 45\% dos consumidores (142 indivíduos) utilizam a embalagem para consultar as instruções de preparo, 31\% (96 indivíduos) relataram não procurar nenhuma informação na embalagem, 16\% (49 indivíduos) procuram receitas e 10\% (31 indivíduos) consultam novamente a lista de ingredientes. Harmonização com bebidas e alimentos foi relatado por apenas $4 \%$ dos participantes (14 indivíduos).

Quando questionados sobre terem preparado receitas contidas nas embalagens de alimentos 65\% (203 indivíduos) relataram já terem preparado enquanto $35 \%$ (111 indivíduos) nunca tentaram. Somado a isto, quando abordados 
sobre onde procuram novas receitas, 68\% dos consumidores (212 indivíduos) relataram recorrer a internet, 20\% (61 participantes) procuram em livros de receitas, 15\% (47 indivíduos) perguntam para amigos, 13\% (41 indivíduos) utilizam cadernos de receitas, e 11\% (35 indivíduos) citaram recorrer a outros meios, como inventar uma receita.

Ao final do questionário os consumidores foram perguntados em questões abertas sobre a forma como gostam de preparar e consumir os alimentos, o que os agrada e desagrada nesses momentos e o que consideram uma embalagem boa e uma embalagem ruim. Uma síntese destas respostas é apresentada no quadro 1, a seguir:

Quadro 1 - Questões abertas do formulário. Elaborado pelos autores.

\begin{tabular}{|c|c|}
\hline $\begin{array}{l}\text { Como gosta de } \\
\text { preparar suas } \\
\text { refeições? }\end{array}$ & $\begin{array}{l}\text { Ouvindo música; assistindo televisão; ouvindo rádio; com amigos; sozinha; } \\
\text { na minha cozinha; de modo organizado; com bebida; acompanhado da } \\
\text { esposa; com outras pessoas ajudando; atento ao preparo; com temperos } \\
\text { frescos; sozinha; em harmonia; de forma prática. }\end{array}$ \\
\hline $\begin{array}{l}\text { Como gosta de } \\
\text { saborear suas } \\
\text { refeições? }\end{array}$ & $\begin{array}{l}\text { Em família; sentados na mesa; na mesa e em silêncio; sem televisão; na } \\
\text { sala de jantar com música; em ambiente limpo e arejado; conversando; } \\
\text { sem barulho; com marido; na cozinha com familiares; vendo televisão; com } \\
\text { amigos; sempre no mesmo horário. }\end{array}$ \\
\hline $\begin{array}{l}\text { O que o agrada } \\
\text { nesses } \\
\text { momentos? }\end{array}$ & $\begin{array}{l}\text { Saber o que está comendo; elogios; saber que vão comer com vontade; } \\
\text { sabor e cheiro do alimento; família; opinião dos outros; ver que está bem } \\
\text { feito; silêncio; boa companhia; tranquilidade; conversar; momento de } \\
\text { tranquilidade do dia; união; saber que fez e foi aprovado; saber que está } \\
\text { servindo coisa boa; fazer a própria comida; satisfação. }\end{array}$ \\
\hline $\begin{array}{l}\text { O que o } \\
\text { desagrada } \\
\text { nesses } \\
\text { momentos? }\end{array}$ & $\begin{array}{l}\text { Não ficar no ponto; noticias ruins; telefone; assunto ruim; discutir } \\
\text { problemas; perturbações; pressa; interrupções; campainha; televisão; } \\
\text { arrumar a louça; barulho; sujeira; obrigação de ser bom; cozinhar sozinha; } \\
\text { cheiro de peixe; não acertar a receita; limpar; conversa. }\end{array}$ \\
\hline $\begin{array}{l}\text { O que é uma } \\
\text { embalagem } \\
\text { boa? }\end{array}$ & $\begin{array}{l}\text { Produto bom, bonito; legível; forte; fácil de abrir; fácil de ler as } \\
\text { informações; transparente; diz a verdade; fácil de servir; segura; bem } \\
\text { fechada; facilite o transporte; biodegradável; que contenha todas as } \\
\text { informações; não estar violada; reciclável; que abre e fecha; prática para } \\
\text { guardar; simples e sem sofisticação; que tenha cor; que tenha informações } \\
\text { sobre sódio; limpa; a vácuo; lacrada; sem muita água; data de validade } \\
\text { visível. }\end{array}$ \\
\hline $\begin{array}{l}\text { O que é uma } \\
\text { embalagem } \\
\text { ruim? }\end{array}$ & $\begin{array}{l}\text { Não ver o produto; que rasga; muitas informações; na hora de servir } \\
\text { espalha; difícil de abrir; o contrário da boa; difícil de transportar; } \\
\text { embalagens frágeis; conservas e embalagens difíceis de abrir; que promete } \\
\text { e não cumpre; de creme de leite; de farinha; feia; com poucas } \\
\text { informações; danificada; que vaza; meio vazia; feia e suja; difícil } \\
\text { degradação. }\end{array}$ \\
\hline
\end{tabular}

A partir da abordagem quanto aos hábitos de consumo de alimentos, sobre a percepção em relação a frutos do mar e em relação a experiência no preparo e consumo de alimentos foram definidos os seguintes requisitos para uma embalagem de produto da maricultura:

- Fácil de ler e encontrar as informações;

- Fácil de abrir e possibilidade de abrir e fechar a embalagem;

- Destaque para data de validade;

- Tabela nutricional com destaque para informações importantes; 
- Utilização de material transparente para visualização do alimento dentro da embalagem;

- Legenda para informações obrigatórias que os consumidores não valorizam;

- Apresentação de modo e temperatura de conservação;

- Fácil de servir e/ou manipular o alimento;

- Integração com site para acesso a receitas;

- Utilização de ícones cores para destacar informações mais procuradas pelos usuários.

A embalagem do tipo pote de vidro com tampa plástica foi utilizada para permitir a abertura e fechamento da embalagem. Esta embalagem permite também fácil remoção do produto e reutilização. A proposta apresentada na Figura 4, a seguir, representa a aplicação dos requisitos na rotulagem da embalagem.
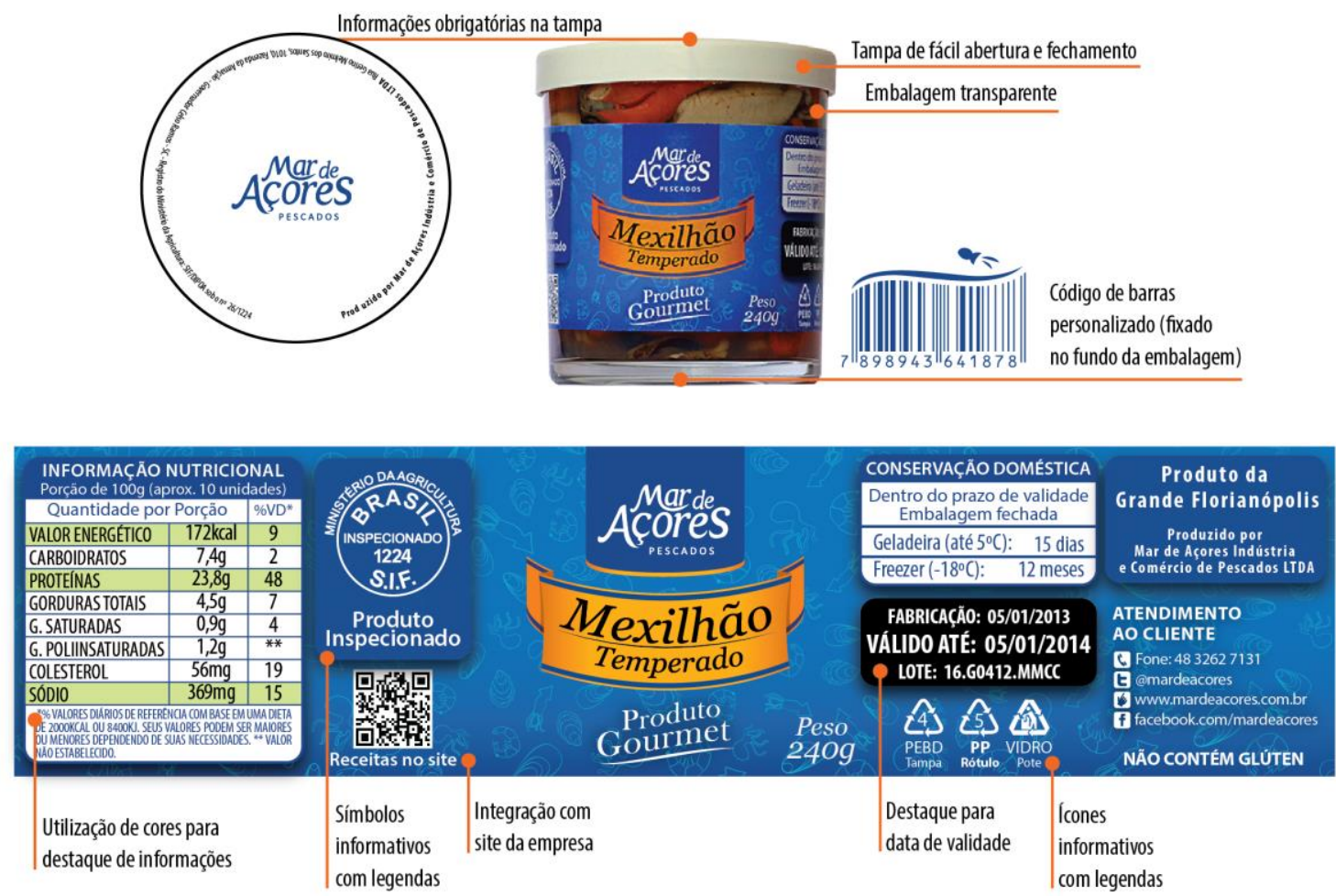

Figura 4 - Aplicação dos requisitos na embalagem. Elaborado pelos autores.

Cabe ressaltar que foi considerada a legislação brasileira para rotulagem de alimentos no desenvolvimento desta pesquisa. O selo "SIF" do Ministério da Agricultura é uma informação obrigatória que deve constar em produtos de origem animal, no entanto, o consumidor não valoriza esta informação, que muitas vezes é considerada um ruído na embalagem. Deste modo, foi criado um selo com uma legenda para a fixação desta informação na embalagem, visando torna-lo um item de diferenciação e valorização do produto.

Os itens mais relevantes (tanto para os consumidores quanto em termos nutritivos) foram destacados nas informações nutricionais. Embora estas informações possam ser apresentadas escritas por extenso, ocupando menos espaço, optou-se por utilizar a forma de tabela para facilitar o acesso às informações. 
O prazo de validade, informação mais procurada pelos consumidores no ato da compra, foi impressa em negativo para facilitar sua localização.

Por se tratar de uma área de rotulagem relativamente pequena, e pelos usuários terem o hábito de consultar a internet para acessarem novas receitas, optouse por fazer referência ao site e orientar os consumidores a procurarem nessa mídia as receitas com o produto. Dessa forma, podem também ser apresentados outros produtos da empresa aos consumidores.

Como forma de reforçar o cuidado e o trabalho artesanal no preparo de alimentos, o código de barras foi personalizado, mostrando a atenção a cada detalhe que a empresa tem com seu produto.

Embora os consumidores prefiram o produto fresco, optou-se por se trabalhar com uma linha beneficiada para que o produto possa ser difundido e alcance novos mercados. Neste contexto, Barni e Rosa (2005) explicam que o processamento de mexilhões além de agregar valor ao produto pode criar e consolidar novos canais de comercialização, e que a diferenciação pela marca e pelo desenvolvimento de novos produtos industrializados semiprontos e prontos para consumo representam alternativas capazes de potencializar a competitividade do produto. Para Bombardelli, Syperreck e Sanches (2005) tal fator está relacionado a tendência moderna de se consumir produtos prontos ou semiprontos, com qualidade e quantidade e que sejam de fácil preparo.

Para Ostrensky e Boeger (2008) o processamento e a industrialização permitem além de agregar valor aos produtos da aquicultura popularizar o consumo do mesmo, expandindo e consolidando a atividade. Nesse sentido Bombardelli, Syperreck e Sanches (2005), explicam que o aumento de consumo de pescados no país só será possível mediante o desenvolvimento de tecnologias de processamento que atendam as exigências dos consumidores. Ademais, Ostrensky, Boeger e Chammas (2008) defendem que apesar da produção de mexilhões no Brasil ter crescido ao longo dos anos, esta chegará a um ponto de estagnação, visto que há a predominância da comercialização do produto desconchado, resfriado e com curto prazo de validade.

Assim, os resultados aqui apresentados contribuem para a Maricultura por meio do desenvolvimento de embalagens que promovam maior satisfação aos consumidores na interação com o produto no ato da compra e consumo de alimentos. Os procedimentos e estratégias utilizados nesta pesquisa foram direcionados para realidade de mercado e empresas do setor da maricultura do estado de Santa Catarina, visando amenizar as dificuldades na comercialização dos produtos.

\section{CONCLUSÃO}

A consideração dos consumidores para o desenvolvimento de projetos de embalagem possibilita um melhor planejamento para os momentos de produção, armazenamento, venda, uso e descarte das embalagens, fortalecendo a comunicação e o posicionamento no mercado, intensificando o potencial competitivo das empresas frente à concorrência. Nesse sentido a pesquisa com consumidores consistiu em uma etapa fundamental desta pesquisa, permitindo o levantamento de suas necessidades e desejos em relação às embalagens, fortalecendo a etapa de criação das mesmas.

Quanto ao objetivo da pesquisa (definir requisitos para uma embalagem) observa-se que esta ação fortalece a atividade de design como uma atividade sistemática. A definição de requisitos, somada às demais etapas sugeridas pelo GODP, 
tornaram o processo de design mais consistente e trouxeram mais segurança à equipe de projeto, bem como auxiliaram na gestão do tempo.

Com o beneficiamento das empresas, esses resultados se refletem na sociedade, gerando empregos e melhorando a economia, além de disponibilizar uma oferta de produtos que atendem mais adequadamente às demandas dos consumidores.

Como futuros estudos, acredita-se que esta pesquisa possa ser continuada a partir de novos testes com consumidores a partir da embalagem desenvolvida.

\section{AGRADECIMENTOS}

À Coordenação de Aperfeiçoamento de Pessoal de Nível Superior (CAPES), ao Conselho Nacional de Desenvolvimento Científico e Tecnológico (CNPq), à Fundação de Amparo à Pesquisa e Inovação do Estado de Santa Catarina (FAPESC) e a Mar de Açores Pescados, pelo apoio a esta pesquisa.

\section{REFERÊNCIAS}

ALTMANN, R.; MIOR, L.C.; ZOLDAN, P. Perspectivas para o sistema agroalimentar e o espaço rural de Santa Catarina em 2015: Percepção de representantes de agroindústrias, cooperativas e organizações sociais. Florianópolis: Epagri, 2008.

BARNI, E. J.; ROSA, R. de C.C. Competitividade das cooperativas de mitilicultores de Santa Catarina. Florianópolis: Epagri, 2005.

Bombardelli, R. A.; Syperreck, M. A.; Sanches, E. A. Situação atual e perspectivas para o consumo, processamento e agregação de valor ao pescado. Arquivo de Ciência e Veterinária e Zoologia da UNIPAR, v. 8, n. 2, p. 181-195, 2005.

DICKIE, I. B. Gestão de design aplicada: estratégias de comunicação no contexto do desenvolvimento sustentável. 2010. 173f. Dissertação (Mestrado em Design Gráfico) Programa de Pós-Graduação em Design e Expressão Gráfica, UFSC, Florianópolis, 2010.

FAO. El estado mundial de la pesca y la acuicultura - 2010. Organización de las Naciones Unidas Para la Agricultura y la Alimentación. Departamento de Pesca y Acuicultura de la FAO. Roma, 2010.

GARCIA, L. J. A Gestão de Design para o Desenvolvimento e Valorização de Produtos da Maricultura: uma abordagem de usabilidade. 2013. 193 f. Dissertação (Mestrado) Curso de Programa de Pós-graduação em Design e Expressão Gráfica, Departamento de Comunicação e Expressão Gráfica, Universidade Federal de Santa Catarina, Florianópolis, 2013.

GARCIA, L. J.; MERINO, E. A. D. A gestão de Design e seu impacto no desenvolvimento de projetos aplicados na área de embalagem e rotulagem da aquicultura familiar. Relatório de Projeto de pesquisa Parte I CNPq Edital 2007. Florianópolis: Núcleo de Gestão de Design / Universidade Federal, de Santa Catarina, 2008.

GARCIA, L. J.; MERINO, E. A. D. A gestão de Design e seu impacto no desenvolvimento de projetos aplicados na área de embalagem e rotulagem da aquicultura familiar. Relatório de Projeto de pesquisa Parte II CNPq Edital 2007. Florianópolis: Núcleo de Gestão de Design / Universidade Federal, de Santa Catarina, 2009.

GIL, A. C. Como elaborar projetos de pesquisa. 5. ed. São Paulo: Atlas, 2010. 
GIL, A. C. Métodos e técnicas de pesquisa social. 6.ed São Paulo: Atlas, 2008.

HURLEY et al. Effects of private and public label packaging on consumer purchase patterns. Packaging Technology and Science. 30 jan. 2013. Disponível em: <http://onlinelibrary.wiley.com/store/10.1002/pts.2012/asset/pts2012.pdf?v=1\&t=hjb d1r8q\&s=a7298796e83554beb7639cefe2531b6232783620>. Acesso em: 16 jul. 2013.

LAKATOS, E. M.; MARCONI, M. A. Metodologia Científica. São Paulo: Atlas, 2009.

MERINO, E.; MERINO, G.; FIGUEIREDO, L.; F.; G. Design valorizando produtos da agricultura familiar - Hermes de Ré. Florianópolis, EPAGRI, 2007. 109p.

MERINO, G. Metodologia para a prática projetual do Design com ênfase no Design Universal. 2013. 130 f. Qualificação Tese (Doutorado) - Curso de Programa de Pós Graduação em Engenharia de Produção, Universidade Federal de Santa Catarina, Florianópolis, 2013.

MERINO, G. S. A. D.; GONTIJO, L. A.; MERINO, E. A. D. O percurso do design: no ensino e na prática. In: Moraes, D.; Dias, R. A.; Conselho, R. B. Cadernos de estudos avançados em design: método. Barbacena, MG: EdUEMG, 2011.

OSTRENSKY, A.; BOEGER, W. A. Principais problemas enfrentados atualmente pela aquicultura brasileira. In: OSTRENSKY, Antonio; BORGHETTI, José Roberto, SOTO, Dóris. Aquicultura no Brasil: o desafio é crescer. p.135-158. Brasília: FAO, 2008.

OSTRENSKY, A.; BOEGER, W. A.; CHAMMAS, M. A. Potencial para o desenvolvimento da aquicultura no Brasil. In: OSTRENSKY, A.; BORGHETTI, J. R.; SOTO, D. Aquicultura no Brasil: o desafio é crescer. p.159-182. Brasília: FAO, 2008

OSTRENSKY, A; BORGHETTI, J. R.; SOTO, D. Aquicultura no Brasil: o desafio é crescer. Brasília: Organização das Nações Unidas para Agricultura e Alimentação, 2008. 276 p. Disponível em: <http://projetopacu.com.br/public/paginas/202-livro-aquicultura-nobrasil-o-desafio-e-crescer.pdf>. Acesso em: 18 jul. 2013.

PMF. Projeto APL das Ostras participa da 26a Fispal Food Service. Prefeitura Municipal de Florianópolis. Disponível em: <http://portal.pmf.sc.gov.br/sites/fenaostr a/index.php?pagina=notpagina\&noti=2597>. Acesso em: 17 jul. 2013.

ROZENFELD, H. Gestão de desenvolvimento de produtos: uma referência para a melhoria do processo. São Paulo (SP): Saraiva, 2006. 542p.

RUTTER, M.; ABREU, S. A. Pesquisa de mercado. 2. ed São Paulo: Ática, 1994. 77p.

SILVA, D. C.; PASCHOARELLI, L. C.; SILVA, C. P. O design e a usabilidade de garrafas pet para refrigerantes. In: Anais do 12 ERGODESIGN-USIHC. 12 a 16 de agosto de 2012. Natal, RN - Brasil.

SILVEIRA, F. S.; SILVA, F. M. Desempenho da pesca e aquicultura. In: Síntese Anual da Agricultura de Santa Catarina 2010-2011. Empresa de Pesquisa Agropecuária e Extensão Rural de Santa Catarina. EPAGRI. Florianópolis, 2011.

YOXALL et al. Openability: Producing Design Limits for Consumer Packaging. Packaging Technology and Science. V. 19, n.4, p. 219-225, 19 abr. 2006. Disponível em: <http>//onlinelibrary.wiley.com/doi/10.1002/pts.725 /pdf>. Acesso em: 17 jul. 2013. 
ZHOU, X.; DING, Y.; WANG, Y. Proteomics: present and future in fish, shellfish and seafood. Reviews In Aquaculture, Ásia, v. 4, n. 1, p.11-20, 07 mar. 2012. Disponível em: <http://onlinelibrary.wiley.com/doi/10.1111/i.1753-5131.2012.010 58.x/pdf>. Acesso em: 16 fev. 2013. 